\title{
Perencanaan Interior Perpustakaan Umum Daerah Provinsi DKI Jakarta
}

\author{
Klemens Marco ${ }^{1}$, Dwi Sulistyawati ${ }^{2}$, Ferdinand ${ }^{3}$ \\ Prodi Desain Interior, Fakultas Seni Rupa dan Desain, Universitas Tarumanagara \\ klemens.615160071@stu.untar.ac.id
}

\begin{abstract}
Abstrak- Di era globalisasi ini manusia membawa perubahan dari zaman ke zaman yang terus bergulir hingga saat ini. Ilmu pengetahuan dan teknologi yang membutuhkan wadah untuk berkembang dan disampaikan kepada orang lain membutuhkan berbagai jenis media yang kian lama kian membanjiri kehidupan manusia. Dari sinilah kemudian cikal bakal perpustakaan lahir. Perpustakaan menurut Undang-Undang Republik Indonesia nomor 43 tahun 2007 pasal 1 ayat 1 tentang perpustakaan bahwa "Perpustakaan adalah institusi pengelola koleksi karya tulis, karya cetak dan karya rekam secara profesional dengan sistem yang baku guna memenuhi kebutuhan pendidikan, penelitian, pelestarian, informasi dan rekreasi para pemustaka". Perpustakaan sebagai suatu produk jasa tidak dapat menghindari keniscayaan itu. Dengan bermunculan sebagai jasa layanan sejenis seperti toko buku, cafe buku, pusat dokumentasi dan banyak hal lainnya. Perpustakaan menjadi produk jasa yang mau tidak mau harus bertransformasi jika tidak ingin tersingkir oleh produk jasa sejenis lainnya. Konsep tema yang akan diterapkan pada interior Perpustakaan Umum Daerah Provinsi DKI Jakarta adalah "Delight Touch in a Stilty Environment". Tema ini dianggap tepat untuk menjadi dasar dan meraih tujuan serta visi misi yang dimiliki Perpustakaan Umum Daerah Provinsi DKI Jakarta. MeRedesain Perpustakaan Umum Daerah DKI Jakarta diharapkan dapat Menciptakan interior Perpustakaan Umum Daerah DKI Jakarta yang baru dengan image yang lebih baik, Memberikan kenyaman ketenangan dan keamanan untuk pengunjung perpustakaan dengan interior yang baru serta Memberikan kesan yang positif kepada pengunjung dengan fasilitas yang ada dan lingkungan yang positif melalui proses analisa perpustakaan dan konsep perancangan interior yang baik yang menggambarkan citra dari perpustaan tersebut dengan mengikuti perkembangan zaman.
\end{abstract}

Kata kunci: Interior, Buku, Perpustakaan, Perpustakaan Jakarta.

\section{PENDAHULUAN}

Bagian ini menjelaskan latar belakang permasalahan, studi literatur dan tujuan penelitian. Beberapa paragraf awal bagian pengangar menjelaskan persoalan dan latarbelakang persoalan tersebut. Beberapa paragraf berikutnya menjelaskan kajian pustaka yang berisi perkembangan pengetahuan terkini yang secara langsung terkait dengan persoalan yang diangkat. Paragraf terakhir dari bagian pe-ngantar berisi permasalahan dan deskripsi tujuan penelitian.

Kajian pustaka tidak dituliskan sebagai bagian terpisah, namun masuk ke dalam Pendahuluan, Metode dan Pembahasan. Pustaka yang di acu harus ada dalam Daftar
Referensi. Acuan Relevan, mutakhir, acuan primer/jurnal.

\section{METODE}

Berikut rangkaian metode perancangan yang digunakan dalam mewujudkan proyek Perancangan Interior Perpustakaan Umum Daerah DKI:

Teknik Pengumpulan Data

A. Studi Literatur

Penelitian dengan mengumpulkan data literature dari berbagai sumber yang resmi dari internet maupun buku-buku yang berhubungan dengan perancangan perpustakaan maupun tentang perpustakaan itu sendiri.

B. Studi Observasi 
Teknik pengumpulan data dengan mengadakan penelitian dan peninjauan langsung ke. Studi observasi dilakukan dengan cara :

1. Survey Lapangan

Mengunjungi langsung perpustakaan dan mendata kendala-kendala yang ada di lokasi mencangkup aspek-aspek yang telah ditentukan.

2. Wawancara

Wawancara dilakukan dengan pihak perpustakaan, yaitu untuk mengetahui tentang penyimpanan koleksi, alur masuk dan keluar koleksi dan sistem klasifikasi koleksi, penyimpanan arsip, alur masuk dan keluar arsip, serta sistem utilitas, keamanan bangunan.

3. Dokumentasi

Dokumentasi dilakukan untuk mengumpulkan data berupa foto-foto ruangan, denah bangunan, struktur organisasi, data pengunjung.

Tahap Perancangan :

A. Programming

Penyusunan data-data yang telah didapatkan dari hasil survei kemudian disesuaikan dengan standar kenyamanan perpustakaan.

B. Konsep Desain

Rancangan tema, gaya yang telah disesuaikan dengan programming.
C. Gambar Kerja

1. Site plan \& Layout Plan / Layout Furniture

2. Layout Floor

3. Ceiling plan

4. Potongan

5. Tampak

D. Gambar Presentasi

1. Layout

2. Perspektif

3. Tampak

E. Skematik material dan warna

\section{HASIL DAN PEMBAHASAN}

DKI Jakarta adalah sebuah perpustakaan umum yang didirikan oleh pemprov DKI Jakarta sebagai suatu wadah pelayanan informasi dan juga kearsipan.Perpustakaan ini terbuka untuk semua kalangan bahkan untuk pengunjung yang berasal dari luar Jakarta.

Disamping fasilitas perpustakaan dan kearsipan, Perpustakaan Umum Daerah Provinsi DKI Jakarta juga menyediakan bermacam-macam fasilitas yang bisa dinikmati secara gratis untuk pengunjungnya antara lain :

- Layanan Perpustakaan Anak

- Layanan Koleksi Braile

- Layanan Internet

- Layanan E-Library (Jakartapedia, E-Book Dan

E-Journal)

- Layanan Audio Visual 
- Layanan Referensi

- Layanan Koleksi Khusus Jakarta

- Layanan Pesan Antar Koleksi Perpustakaan

- Layanan Bimbingan Pemustaka

- Layanan Fotokopi Gratis Untuk Anggota

Perpustakaan

- Layanan Perpustakaan Masyarakat Jakarta

(Permata)

- Wi Fi Area

- Ruang diskusi

- Ruang Pameran

- Ruang bermain anak

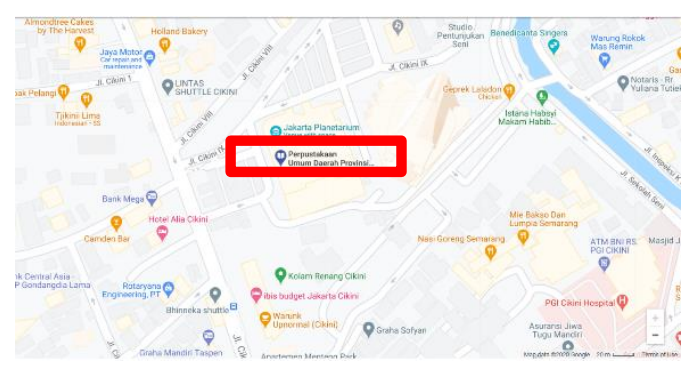

Gambar 1. Tampak satelit Perpustakaan Umum Daerah Prov DKI Jakarta

(Sumber: https://www.google.com)

Terletak di Taman Ismail Marzuki Jl. Cikini

Raya No.73, RT.8/RW.2, Cikini, Kec. Menteng, Kota Jakarta Pusat, Daerah Khusus Ibukota Jakarta 10330

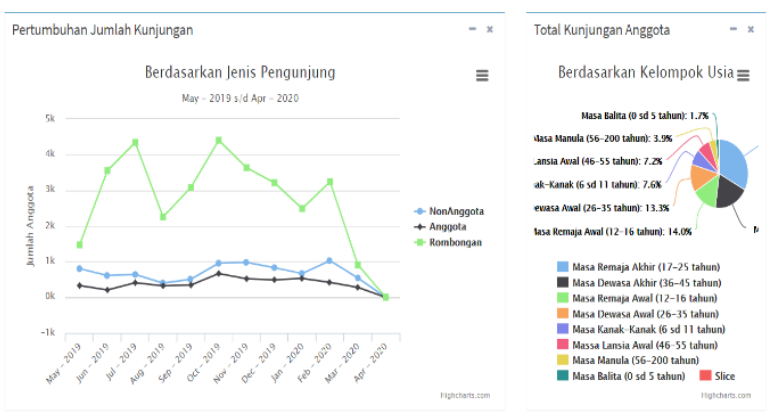

Gambar 2. Data statistic pengunjung perpustakaan umum daerah prov DKI Jakarta
(Sumber:

http://inlislite.dispusip.jakarta.go.id/pustaka/statistikperkembangan-perpustakaan)

Berdasarkan data statistic diatas. Pengunjung dibagi menjadi 2 kelompok pengunjung.

Pertama pengunjung dewasa meliputi kelompok Remaja awal hingga dewasa akhir karena aktifitas dari keempat kelompok tersebut hampir sama dan sisanya berada pada kelompok anak-anak.

Terdapat juga pengguna non pengunjung yang akan dikelompokkan ke dalam pengguna staff yaitu pengurus dan pengelola perpustakaan.

Berdasarkan data statistic diatas pula.Analisis besaran ruang dibuat berdasarkan data statistic ini. Perkiraan kotor diambil dari 4500: 30 dan 1500:30(jumlah hari dalam 1 bulan). 50 - 150 (perkiraan kotor) pengunjung perharinya.

Konsep tema diambil berdasarakan pertimbangan dari konsep citra dan suasana adalah:

\section{"Delight Touch in Stilty Environment"}

Konsep perpustakaan yang resmi namun harus tetap dapat menarik dan menyenangkan orang untuk datang, dengan tetap menjaga semua fungsi dan esensi dari perpustakaan itu sendiri, dan menegaskan citra dari pendiri perpustakaan ini yang adalah 
Fakultas Seni Rupa dan Desain - Universitas Tarumanagara

Klemens Marco, Dwi Sulistyawati, Ferdinand; Halaman 17 -24

sebuah instansi resmi pemerintahan.

Dengan mengkombinasikan elemen-elemen yang bersifat kaku atau tegas dan mengimbanginya dengan elemen-elemen yang bermain seperti garis diagonal maupun garis lengkung serta penggunaan material dengan warna primer.

gaya yang tepat untuk dipakai dalam mengakomodasi isi dari konsep-konsep diatas adalah gaya desain yang kontemporer / modern. Gaya kontemporer terkesan lebih kaku dan bentuk-bentuk yang biasa ditampilkan lebih fleksibel dan variatif, sehingga cocok untuk digunakan pada perancangan perpustakaan kali ini yang mengusung tema kaku namun juga terkesan ada elemen bermainnya.

\section{AREA LOBBY}

Area lobby terdiri dari area tunggu dan resepsionis termasuk kedalam area penerimaan perpustakaan, sehingga merupakan area yang pertama kali dan pasti akan didatangi. Maka untuk area resepsionis ini harus memberikan kesan yang profesional serta berwibawa.

Pada area resepsionis dan area tunggu menggunakan material-material yang memberi kesan elegan seperti dinding panel yang bermotif marmer, finishing lantai bermotif batuan travertine, selain itu terdapat sedikit ornament-ornamen yang diambil berdasarkan bentuk asli dari ornament khas betawi seperti pada panel samping resepsionis dan pada lisplang ceiling meja resepsionis yang diolah lagi menyesuaikan karakter dan bentuk pada ruang. Menggunakaan temperature pencahayaan di sekitar 3000K agar menambah kesan hangat dan santai ditengah kesan yang elegan.

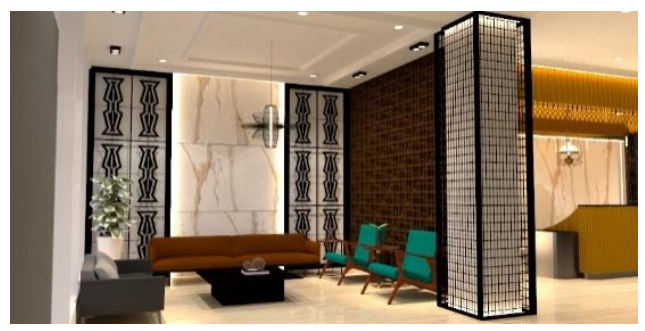

Gambar 3. gambar perspektif view 1 tunggu lobby (Sumber: pengolahan pribadi)

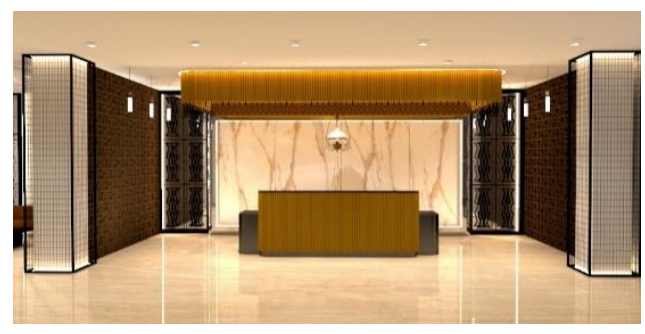

Gambar 4. gambar perspektif view 1 area resepsionis lobby

(Sumber: pengolahan pribadi)

\section{AREA PELAYANAN}

Area pelayanan perpustakaan yang masuk dalam lingkup perancangan proyek ini hanyalah pada area penyimpanan koleksi dewasa, area membaca, area digital, dan area membaca private. Area pelayanan merupakan area utama pada proyek ini yang dimana hampir segala aktivitas-aktivitas akan 
Fakultas Seni Rupa dan Desain - Universitas Tarumanagara

Klemens Marco, Dwi Sulistyawati, Ferdinand; Halaman 17 -24

dilakukan pada area ini, maka disamping nyaman area pelayanan ini juga harus dapat mendukung segala aktivitas-aktivitas yang dilakukan didalamnya.

Area pelayanan dibuat dengan menunjukan kesan yang santai ditengah-tengah suasana yang serius maupun tegas. Menampilkan garis yang lurus dan tegas ditambah beberapa garis diagonal dan sedikit garis lengkung untuk memberi kesan yang dinamis dan juga bermain agar suasana ruang tidak terlalu kaku. Menggunakan temperature warna di kisan 4000K untuk pencahyaan utama dan sedikit 3000K untuk ambience light sebagai penghangat suasana.

\section{A. Area penyimpanan koleksi dewasa}

Area koleksi cukup memberi kesan tegas lewat bentuk-bentuk pada elemen ruang yang terkesan lurus dan tajam, juga pada pemilihan material yang didominasi penggunaan $\mathrm{hpl}$ yang bermotif kayu memberi kesan hangat. Namun untuk mengimbangi kesan kaku tersebut area membaca disini diimbangi dengan garis-garis yang miring untuk memberi kesan bermain, dapat dilihat pada bentuk furniture yang memiliki banyak elemen garis miring, serta penggunaan warna merah di beberapa elemen untuk menambah kesan bermain.

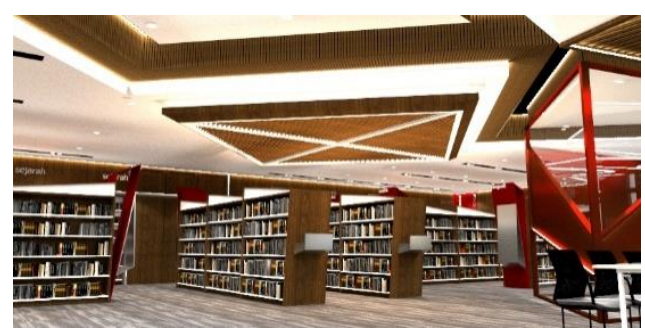

Gambar 5. gambar perspektif view 1 area koleksi dewasa

(Sumber: pengolahan pribadi)

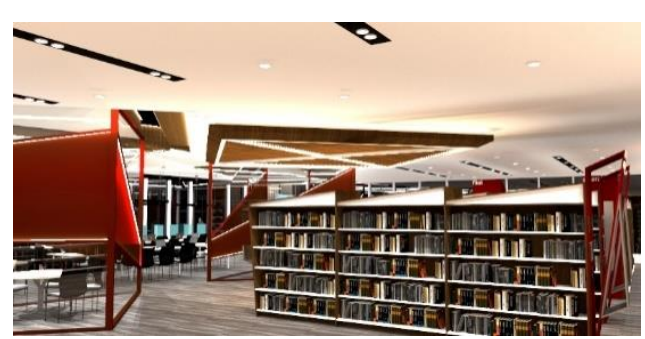

Gambar 6. gambar perspektif view 2 area koleksi dewasa

(Sumber: pengolahan pribadi)

\section{B. Area baca}

Area baca lebih menonjolkan kesan yang agak bermain, terlihat pada bentuk-bentuk elemen interior yang disajikan khususnya pada ceiling. Bentuk ceiling di area diisi dengan bentukbentuk geometris triangular (segitiga) dengan pengolahannya yang ditambah kisi-kisi serta treatment pada pengolahan plafon lainnya yang dilengkapi dengan led hidden light menampilakan bentuk yang unik. Area membaca letaknya menyatu langsung dengan ruang diskusi kecil sehingga sangat mempengaruhi tampilan area baca, pengolahan desain pada ruang diskusi kecil juga senada dengan area membaca, menunjukan kesan yang cukup bermain mulai 
Fakultas Seni Rupa dan Desain - Universitas Tarumanagara

Klemens Marco, Dwi Sulistyawati, Ferdinand; Halaman 17 -24

dari bentuk ruang yang segitiga serta elemen

dinding kaca dengan aksen bentuk diagonal memberi kesan dinamis namun kaku dan juga peletaknnya yang diagonal.
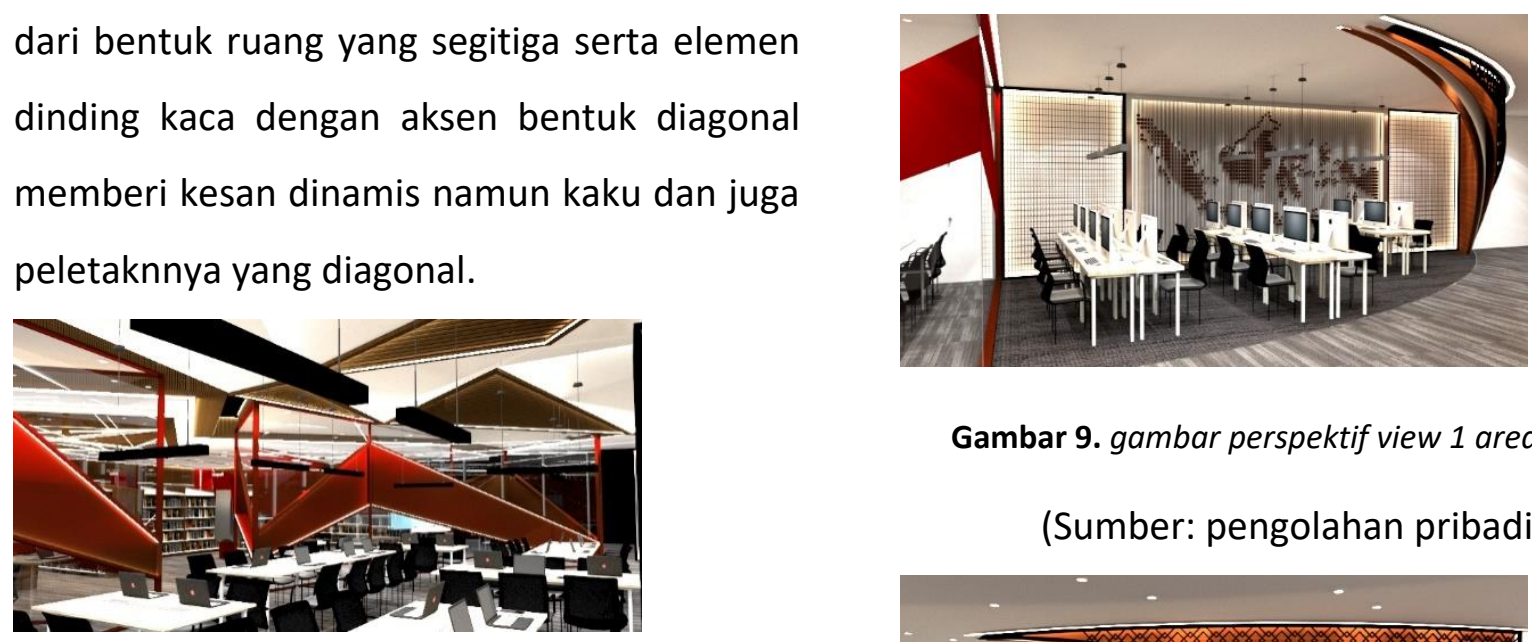

Gambar 9. gambar perspektif view 1 area digital (Sumber: pengolahan pribadi)

Gambar 7. gambar perspektif view 1 area membaca (Sumber: pengolahan pribadi)

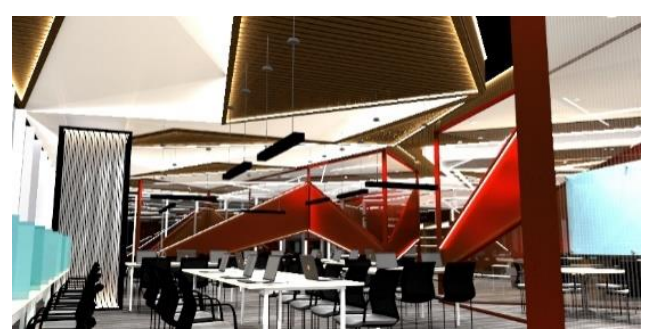

Gambar 8. gambar perspektif view 2 area membaca

(Sumber: pengolahan pribadi)

\section{Area perpustakaan digital}

Pada area perpustakaan digital terdapat panel dinding pembatas area ruang dengan bentuk yang melengkung memberi kesan bermain dengan penyusunan panel yang berlapis membuat area ruang terlihat dinamis, selain itu di panel sisi lainnya terdapat hiasan dekoratif peta Indonesia yang ditutup dengan panel kombinasi plat stainless dan wiregrid memberi kesan yang kaku dengan garis-garis dan bentuk tajam yang dihasilkan.

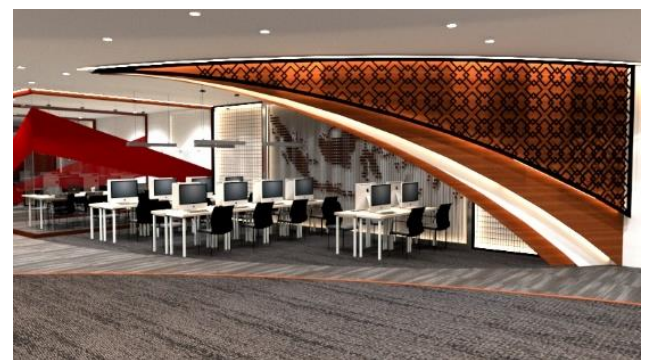

Gambar 10. gambar perspektif view 2 area digital

(Sumber: pengolahan pribadi)

\section{Area membaca privat}

Pada area ini juga menggunakan panel melengkung berlapis yang sama dengan area perpustakaan digital, pemasangannya yang saling berhadapan namun berbeda arah memberi kesan yang unik pada ruangan, menggunakan aksen finishing berwarna tosca pada masing-masing sekat ruang membaca membuat suasana ruang menjadi lebih fun dan modern namun simple.

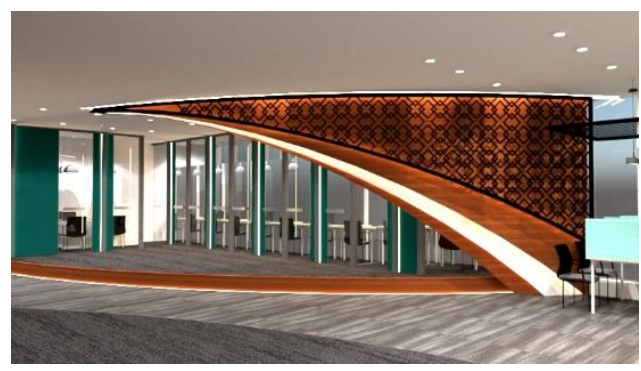

Gambar 11. gambar perspektif view 1 area membaca privat 


\section{SIMPULAN}

Pada perancangan interior Perpustakaan Umum Daerah Provinsi DKI Jakarta ini dapat disimpulkan bahwa perancangan lebih berfokus untuk mengubah image perpustakaan yang pada umumnya terkesan monoton, kaku, atau serius menjadi suatu tempat yang menyenangkan, yang selain sebagai sumber informasi atau edukasi, namun juga bisa mewadahi berbagai keperluan masyarakat seperti berdiskusi, bersantai, hingga melepas kepenatan dengan sambil memperkaya informasi dan edukasi.

Sehingga lewat proses perancangan melalui konsep-konsep yang telah dibuat, diharapkan pengunjung khusunya warga Jakarta tidak lagi menganggap perpustakaan sebagai tempat yang membosankan sehingga dapat mengajak masyarakat untuk sering datang berkunjung ke perpustakaan untuk membaca.

\section{UCAPAN TERIMA KASIH}

Penulis menyadari bahwa tanpa adanya bimbingan, bantuan, dan doa dari berbagai pihak, jurnal ini tidak dapat terselesaikan dengan tepat waktu. Oleh karena itu, penulis mengucapkan terima kasih dan penghargaan yang setinggi- tingginya kepada:
DOI: http://dx.doi.org/10.24912/jurnal.v17i1.17373

1. Tuhan yang Maha Esa oleh karena berkat dan rahmat-Nya bagi penulis sampai saat ini

2. Perpustakaan Umum Daerah Provinsi DKI Jakarta yang telah mendukung segala sarana dan kebutuhan dalam proses penelitian dan observasi serta segala proses analisis yang berhubungan dengan perpustakaan ini.

3. Seluruh jajaran dan staff petugas Perpustakaan Umum Daerah Provinsi DKI Jakarta yang teelah membantu dalam segala proses observasi hingga analisis.

\section{DAFTAR PUSTAKA}

Basuki, Sulistyo. 1991. Pengantar IImu Perpustakaan. Jakarta: PT. Gramedia Pustaka Utama.

Kamus Besar Bahasa Indonesia. 1998. Jakarta: Balai Pustaka.

Lasa HS. 2005. Manajemen Perpustakaan.

Yogyakarta: Gama Media.

Neufert, Ernest and Peter. 2000. Neufert

Architects' Data: Third Edition. United

Kingdom: Blackwell Publishing.

NS, Sutarno. 2003. Perpustakaan dan

Masyarakat. Jakarta: Yayasan Obor Indonesia. 
Nurmianto, Eko. 2004. Ergonomi Konsep

Dasar dan Aplikasinya: Edisi Ke-2.

Surabaya: Guna Widya.

Panero, Julius dan Martin Zelnik. 2003.

Dimensi Manusia dan Ruang Interior.

Jakarta: Erlangga.

Satwiko, Prasasto. 2008. Fisika Bangunan.

Yogyakarta: Andi.

Soeatminah. 1992. Perpustakaan,

Kepustakawanan dan Pustakawan.

Yogyakarta: Kanisius.

Suwarno, Wiji. 2006. Dasar-Dasar Ilmu

Pendidikan. Yogjakarta: AR-Ruzz Media.

Ching, Francis .D.K. Ilustrasi Desain Interior.

Jakarta: Erlangga. 1996.

Panero, Julius dan Martin Zelnik. Dimensi

Manusia dan Ruang Interior. Jakarta :

Erlangga. 1979.

Thompson, Godfrey. Planning and design of

library buildings. London: Architectural Press.

1973. 